\title{
An Empirical Study on Relationship between Economic Growth and Carbon Emissions Based on Decoupling Theory
}

\author{
Xingjun $\mathrm{Ru}^{1}$, Shaofeng $\mathrm{Chen}^{2}$ \& Hongxiang Dong ${ }^{1}$ \\ ${ }^{1}$ Department of Management, University of Science and Technology of China, Hefei, China \\ ${ }^{2}$ Institute of Policy and Management, Chinese Academy of Science, BeiJing, China \\ Correspondence: Xingjun Ru, Department of Management, University of Science and Technology of China, \\ Hefei 230026, China. E-mail: rxj1986@163.com
}

Received: May 21, 2012 Accepted: June 24, 2012 Online Published: July 18, 2012

doi:10.5539/jsd.v5n8p43 URL: http://dx.doi.org/10.5539/jsd.v5n8p43

\begin{abstract}
This article is based on Tapio's decoupling model theory, make a quantitative evaluation on the relationship between economic development and carbon dioxide emissions in 6 typical developed countries, that is the United States, Canada, Japan, United Kingdom, France, Sweden, and 3 typical developing countries, that is China, Brazil and India. We find that strong decoupling between economic development and carbon emissions occurs in all developed countries and at least once in every country; 6 developed countries' decoupling trends are continued in the entire target research phase; decoupling trends in 3 typical developing countries had substantial differences. Generally speaking, developing countries' decoupling elasticity values are significantly higher than developed countries' decoupling elasticity values in the entire target research phase. The final conclusion is that continued decoupling can be achieved; pursuit of achieving strong decoupling between economic growth and carbon emissions should not at the expense of economic regression or economic stagnation, in this sense, positive strong decoupling did not appeared in 3 typical developing countries, it will be take a long time for developing countries to achieve developed countries' decoupling achievements.
\end{abstract}

Keywords: carbon dioxide emissions, economic growth, decoupling, decoupling elasticity

\section{Introduction}

Since 1990s, global climate change issue is becoming increasingly concerned by international community. In the past, carbon dioxide emissions has always been considered as a kind of byproduct of the fuel combustion process, after United Nations framework Convention on Climate Change Kyoto Conference held in 1997, carbon dioxide emissions become one of the international spotlights (Huang et al., 2008). Many countries around the world carry out the study of climate change and tried to develop appropriate policies to reduce greenhouse gases emissions (especially reduce carbon dioxide emissions), in the meantime promoting economic development level, the ultimate goal of a series of measures taken by these countries is to achieve "de-carbonization" in the process of socio-economic development. However, the goal cannot be achieved immediately (Zhuang, 2007). There is usually accompanied with a sharp carbon dioxide emissions increasing in the early stage of economic development, when economic development increased to a certain level, carbon dioxide emissions' growth rate will gradually slow down or may even moved to an opposite direction of economic growth. There is no doubt that the policies about carbon dioxide emissions' reduction will have an important influence on this process. Evaluate the relationship between carbon dioxide emissions and economic development in different stages will be helpful to provide a basis for policy-making.

International communities are usually using decoupling indicators to measure the relationship between carbon dioxide emissions and economic development in recent years (Ester van der Voet et al., 2005). Decoupling indicators are originally used to reflect the asynchronous changes in the relationship between environmental pressures and economic growth, then it is applied to measure the relationship between carbon dioxide emissions and economic development with climate change issue increasingly received global attentions. Many studies about decoupling indicators' expansion, empirical research on decoupling indicators have been carried out, which involving multiple areas, such as transportation, energy consumption, resource utilization, agricultural policies and so on. 
Marzio's study focus on the relationship between carbon dioxide emissions per capita and income per capita in developed countries, he found that there is no strong decoupling occurs, but he also pointed out that green technology is the key factor to promote the decoupling between economic growth and environmental pressures (Marzio, 2003); Tapio made a decoupling study on relationship of Finland transport sector's carbon dioxide emissions and GDP, and tried to put forward a new criteria for the classification of decoupling indicators (Petri, 2005); Li Jianming studied on the decoupling relationship between Taiwan carbon dioxide emissions and economic development, he pointed out that the key problem to realize decoupling between carbon dioxide emissions and economic development is reducing energy consumption per capita rather than improving energy efficiency ( $\mathrm{Li}$ et al., 2005); Annabelle studied on the decoupling relationship between New Zealand carbon dioxide emissions and economic development, she considered that although the recent relationship between New Zealand's GDP and carbon dioxide emissions experienced a weak relative decoupling, this is just a transient phenomenon, New Zealand cannot achieve a real decoupling in the short term, she suggested that policy makers should regard decoupling indicators as a tool to measure the implementation status of environmental policy (Annabelle, 2007); Yang Ke, Chen Baiming and Song Wei made a decoupling study on the relationship between cultivated land occupation areas and GDP growth in Hebei province (China), they found that the relationship between farmland used for construction in Hebei Province and the non-agricultural GDP output showed a M-shaped curve in 1990-2007, farmland protection policy implementation is effective (Yang et al., 2009); Wang Chongmei applied decoupling model to analyze the relationship between China economic development and energy consumption in 1990-2007, she found that the relationship between China economic development and energy consumption achieves absolute decoupling or relative decoupling in some stages (Wang, 2010); Julia K. Steinberger and J. Timmons Roberts (2010) investigated the relationship between human needs, energy consumption and carbon emissions, they observed a previously undetected decoupling of the energy use per capita and carbon required for human needs through conducting a novel longitudinal analysis from 1975 to 2005; V. Andreoni and S. Galmarini (2012) researched the decoupling relationship between economic growth and carbon dioxide emissions in Italian by the way of making a decomposition analysis of Italian energy consumption, they found that from 1998 to 2006, Italian economy not performed an absolute decoupling in terms of energy consumption and $\mathrm{CO}_{2}$ emissions; $\mathrm{Ru}$ et al. (2012) investigated the driving forces of carbon dioxide emissions, meanwhile they found that with the evolutionary process of carbon dioxide emissions driven by technical advances over time, decoupling phenomenon in carbon dioxide emissions intensity, carbon dioxide emissions per capita, and total carbon dioxide emissions would appeared in turn.

However, most decoupling studies only pay attentions to a single country or a single region, there is little research focus on the cross-countries and cross-regional comparative analysis, moreover, target research period is generally short, which is not conducive to study the decoupling relationship between carbon dioxide emissions and economic development in long time series. This article is going to make a comparative analysis on decoupling relationship between carbon dioxide emissions and economic development in 6 typical developed countries and 3 typical developing countries in 1960-2007, and will put emphasis on analyzing decoupling similarities and differences among developing countries and developed countries, try to seek possible causes of decoupling. This article choose 6 typical developed countries (that is America, Canada, Japan, Britain, Sweden and France), 3 typical developing countries (that is China, Brazil and India) as research objects, and make quantitative evaluation on relationship between carbon dioxide emissions and economic development on 9 typical countries. Total carbon dioxide emissions in these target countries in this study are accounting for the vast majority of the world's total carbon dioxide emissions, emission reduction policies and measures taken in these countries will play an important role in reaching international greenhouse gas emission reduction targets.

\section{Methodologies}

As early as 1966, economic growth depends on the consumption of materials highly for a long time, in order to investigate methods on decreasing this dependence, some scholars have proposed the concept of decoupling in describing asynchronous changes' relationship between economic development and material consumption. After this, decoupling indicators are gradually being introduced into environment research field. Organization for Economic Co-operation and Development (OECD, 2002) thinks that decoupling means a process of breaking the relationship between environmental bads and economic goods or the relationship between environmental pressures and economic performance, meanwhile OECD design the decoupling indicators on the basis of Driving Force - Pressure - State - Impact - Response framework, so as to reflect relative change between environmental pressures' growth and its driving forces' growth in a certain period, this relative change can be quantified as decoupling index or decoupling elasticity, that is:

$$
\mathrm{m}=\% \Delta \mathrm{EP} / \% \Delta \mathrm{DP}
$$




$$
\mathrm{DR}=(\mathrm{EP} / \mathrm{DP})_{\mathrm{t} 1} /(\mathrm{EP} / \mathrm{DP})_{\mathrm{t} 0}
$$

In Equation (1), m means decoupling elasticity, EP represents environmental pressures, DP represents economic factors which causing environmental pressures, $\% \Delta \mathrm{EP}$ and $\% \Delta \mathrm{DP}$ represent change rates of environmental pressures and economic factors separately, subscript of $t_{1}$ and $t_{0}$ represent beginning and end of a research period.

The relative decoupling occurs when economic growth and environmental pressures growth moves toward the same direction but economic growth is moving faster than environmental pressures growth; absolute decoupling occurs when economic growth is increasing but environmental pressures growth keeping the same situation or decreasing. The basic principle of OECD decoupling index/ decoupling elasticity model can be showed as Figure 1.

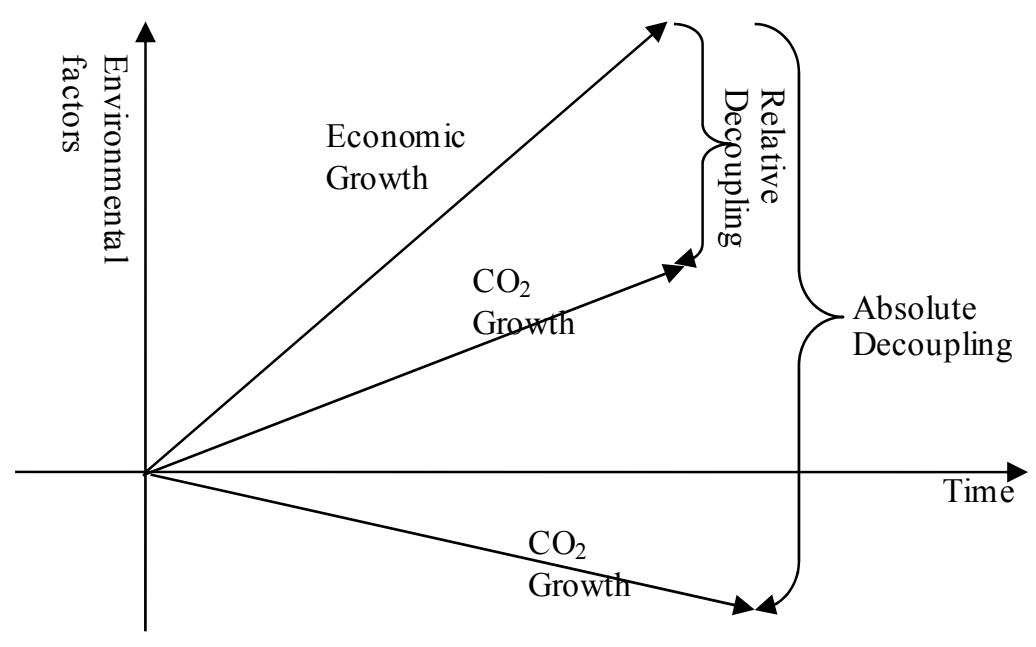

Figure 1. OECD decoupling index/ decoupling elasticity model

However, the concept of relative decoupling and absolute decoupling cannot meet all the descriptions of the relationship between environmental pressures and economic growth. On the one hand, the situation of environmental pressures growth moves faster than economic growth cannot be avoided; on the other hand, some economies cannot avoid economic growth decrease. Based on above reasons, Vehmas et al. built a comprehensive framework considering the different aspects of decoupling. They used the concept of de-linking, reflecting the terminology used in environmental economics, in this article the term decoupling is applied as it is used more often in many decoupling studies, Vehmas et al. also use the concept of re-linking, which is also called negative decoupling (Vehmas et al., 2003). Tapio extended Vehmas' decoupling indicators' classification, he divided decoupling indicators into 3 major categories, that is weak decoupling, economic growth and environmental pressures both increase (and $0<$ decoupling elasticity $<0.8$ ); strong decoupling occurs when both economic growth and environmental pressures decreases (and decoupling elasticity $<0$ ), and recessive decoupling occurs when economic growth and environmental pressures both decrease (and decoupling elasticity $>1.2$ ). Similarly, negative decoupling includes three categories: in expansive negative decoupling economic growth and environmental pressures both increase (decoupling elasticity $>1.2$ ), in strong negative decoupling economic growth decreases and environmental pressures increases (decoupling elasticity $<0$ ) and weak negative decoupling occurs when both variables are decreasing ( $0 \leq$ decoupling elasticity $<0.8)$ (Petri Tapio, 2005). Tapio's decoupling model can be showed as Figure 2 (in Figure 2, $\mathrm{m}$ represents decoupling elasticity, $\mathrm{m}=\% \Delta \mathrm{EP} \% \Delta \mathrm{DP}$ ). 


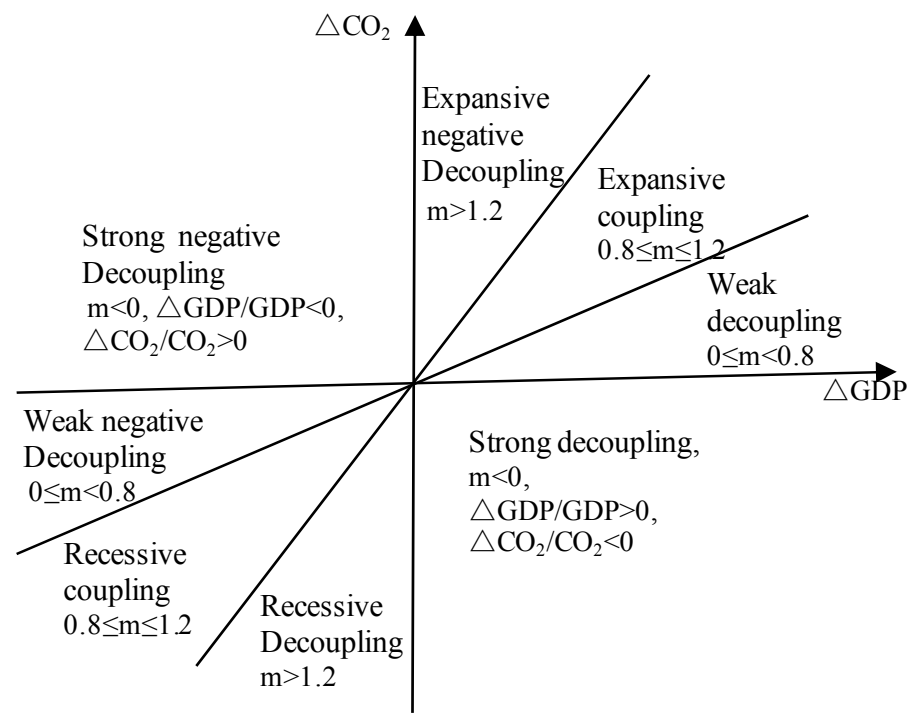

Figure 2. Tapio's decoupling model

\section{An Empirical Research on Decoupling Relationship between Carbon Dioxide Emissions and Economic Growth}

\subsection{Data Sources}

This article will analyze the relationship between CDP growth and carbon dioxide emissions' growth in 6 typical developed countries and 3 typical developing countries in 1960-2007 based on Tapio's decoupling model. The data of carbon dioxide emissions are from Carbon Dioxide Information Analysis Center, Oak Ridge National Laboratory (CDIAC, 2010). The data of GDP are from United Nations Environment Programme-GEO online data portal (UNEP, 2010).

\subsection{Results}

In order to facilitate data processing and analyzing, we will divide the target research stage into 8 sub-stages, hence S1-S8 (Section 1- Section 8) represent the stages of 1960-1965, 1966-1971, 1972-1978, 1979-1983, 1984-1989, 1990-1995, 1996-2001, 2002-2007 respectively, results showed in Table 1. According to Tapio's decoupling model, 9 countries decoupling elasticity in 8 sub-stages can be divided into expansive negative decoupling, expansive coupling, weak decoupling and strong decoupling (see Figure 3).

Table 1. 9 countries' decoupling elasticity in 1960-2007

\begin{tabular}{lcccccccc}
\hline Country & $\mathbf{S}_{\mathbf{1}}$ & $\mathbf{S}_{\mathbf{2}}$ & $\mathbf{S}_{\mathbf{3}}$ & $\mathbf{S}_{\mathbf{4}}$ & $\mathbf{S}_{\mathbf{5}}$ & $\mathbf{S}_{6}$ & $\mathbf{S}_{\mathbf{7}}$ & $\mathbf{S}_{\mathbf{8}}$ \\
\hline Canada & 0.96 & 1.57 & 0.21 & -0.23 & 0.42 & 0.25 & 0.58 & 0.48 \\
France & 0.93 & 1.10 & 0.00 & -1.81 & -0.24 & -0.25 & -0.38 & -0.23 \\
Japan & 1.14 & 1.33 & 0.89 & -0.36 & 0.38 & 1.02 & -1.53 & 0.13 \\
Sweden & 0.95 & 0.80 & 0.13 & -3.63 & -0.14 & 1.01 & -1.00 & -0.90 \\
United Kingdom & 0.41 & 0.52 & -0.70 & -2.14 & 0.49 & -0.12 & -0.30 & 0.11 \\
United States & 0.72 & 1.58 & 0.12 & -1.49 & 0.55 & 0.57 & 0.31 & 0.18 \\
China(Mainland) & -26.31 & 1.76 & 1.44 & 0.33 & 0.59 & 0.50 & 0.02 & 1.10 \\
India & 1.83 & 0.76 & 1.72 & 1.79 & 1.39 & 1.16 & 0.70 & 0.63 \\
Brazil & 0.83 & 1.07 & 0.87 & -0.75 & 1.08 & 1.86 & 1.33 & 0.49 \\
\hline
\end{tabular}




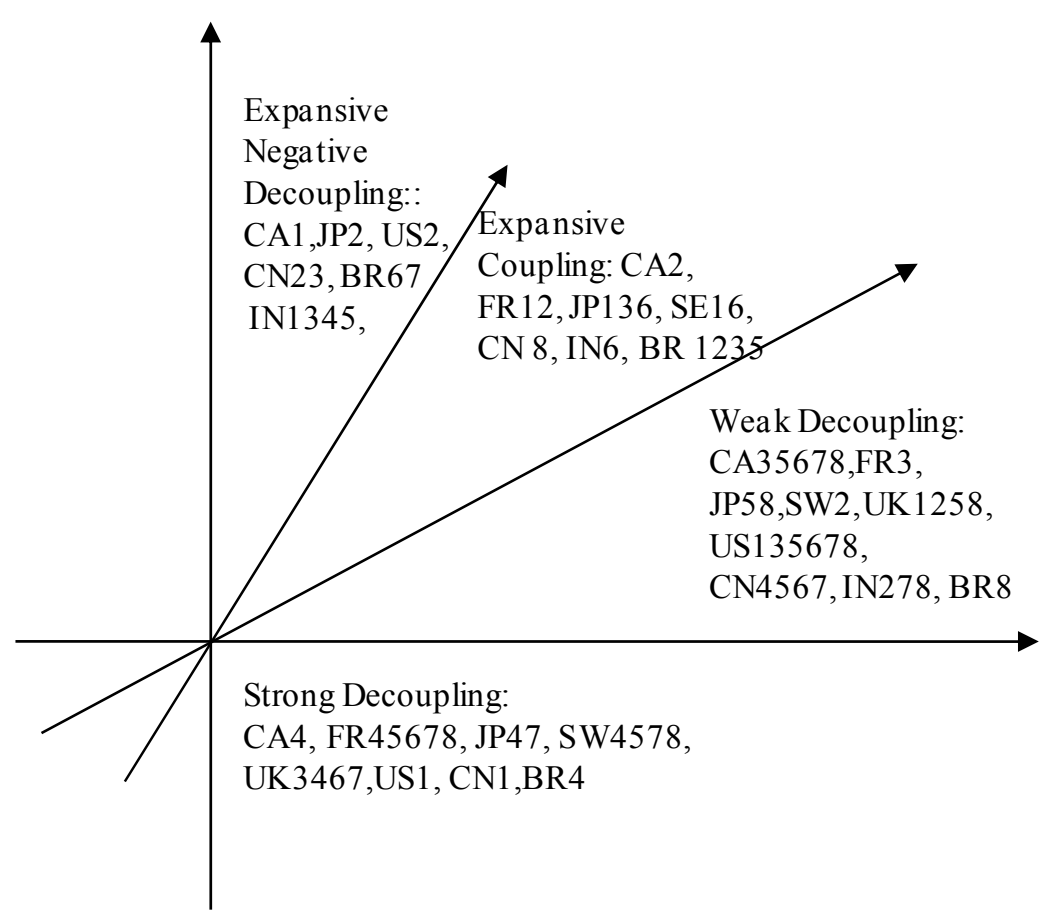

Figure 3. 9 countries' decoupling degree in 8 stages (see Note 1 and Note 2)

\subsection{Comparative Analysis of 9 Countries' Decoupling Indicators}

It can be drawn from the Figure 3 and Table 1 that:

(1) Strong decoupling occursed in 6 typical developed countries

Strong decoupling between carbon dioxide emissions growth and economic growth occurred in every developed country in 8 sub-stages at least once, strong decoupling appeared 5 times in France (that is S4, S5, S6, S7, S8), 4 times in United Kingdom and Sweden (that is S3, S4, S6, S7 and S4, S5, S7, S8 respectively), 2 times in Japan (that is S4 and S7), once in Canada and United States.

From the view of period in which strong decoupling occurs, there are some common points taken place in 6 developed countries. In S4 (1978-1983), 6 developed countries are all realize the strong decoupling between carbon dioxide emissions growth and economic, moreover, France, Japan, United Kingdom and Sweden are all achieve strong decoupling in S7 (1996-2001).

(2) Development trends of 6 developed countries' decoupling elasticity values are consistent in most of research stages

From the perspective of 6 developed countries' decoupling elasticity values development trends, we find that there are some differences in decoupling elasticity values but general development trends of 6 developed countries' decoupling elasticity values is consistent in most of 8 sub-stages. For example, all the developed countries' decoupling elasticity values showed a decline trend from S2 to S4, then all of them going up from S4 to S5, growth rate of 6 developed countries' decoupling elasticity values tended to decrease from S5-S6, however, decoupling elasticity values of 6 developed countries performed a very different trend in the last stage (see Figure 4). This indicates that due to developed countries' higher degree of market-oriented, all of them make a more consistent response to the changes of market-oriented factors. 


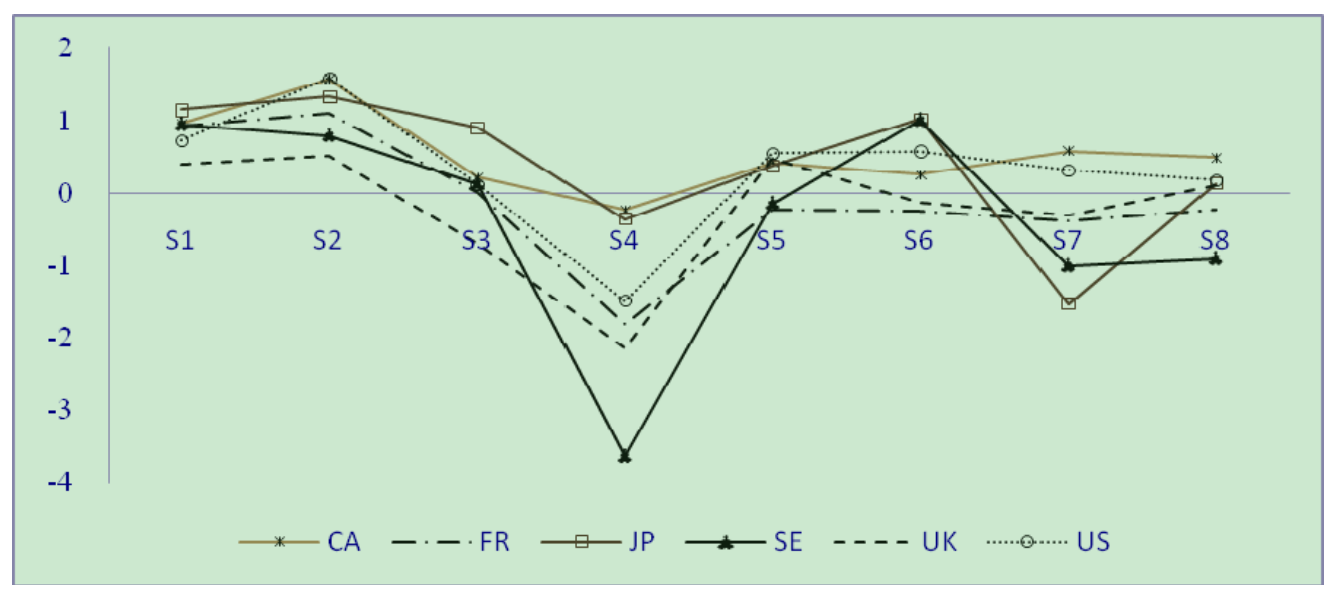

Figure 4. Development trends of 6 developed countries' decoupling elasticity in 8 stages

(3) Decoupling relationships between economic and Carbon dioxide emissions of 3 developing countries are very different

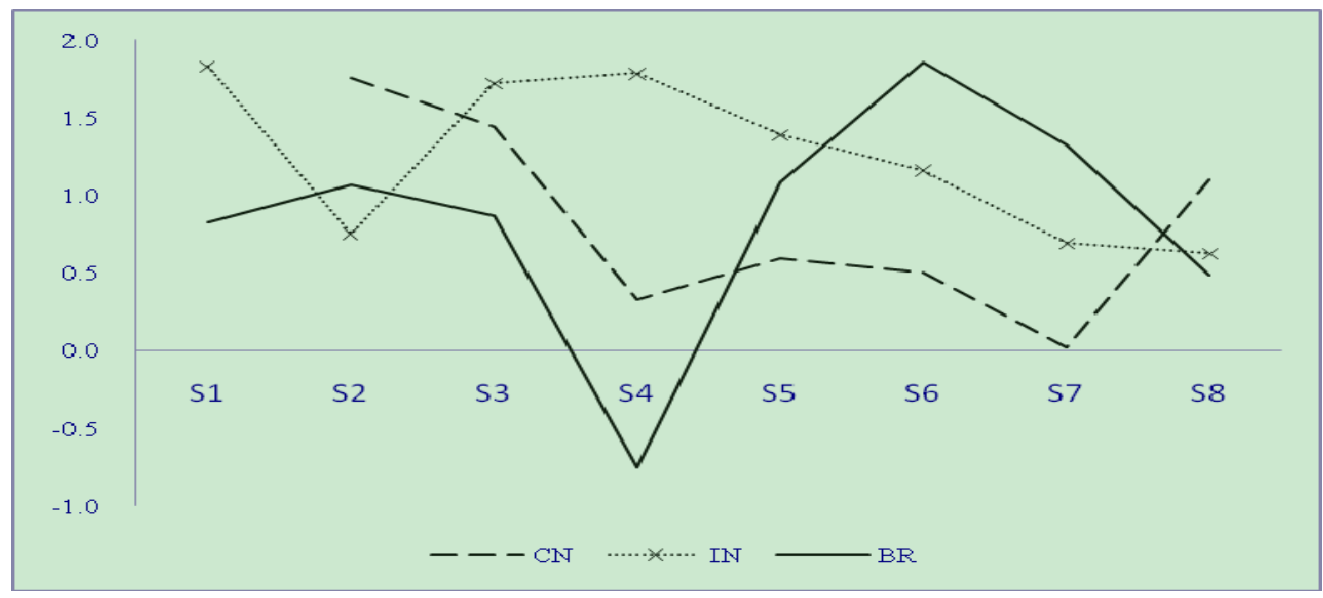

Figure 5. Development trends of 3 developing countries' decoupling elasticity in 8 stages

Development trends of 3 developing countries' decouple elasticity values showed significant differences in 8 sub-stages. Strong decoupling occured in S1 (1960-1965) in China, in order to pursuit of the high-speed in economic development, China hold "reat Leap Forward" development and People Commune movement in 1958-1960 which lead to a serious imbalance of national economy and a severe blow to people's production enthusiasm, which result in the great society in the following three years (1959-1961). Although some policy mistakes are corrected and some national economic development policies are adjusted, due to the lag of policies' effects, China average annual carbon emissions reduction rate is $9.42 \%$. and average annual economic growth rate is just $0.36 \%$ in S1, China decoupling elasticity in S1 is -26.31 ; because of China Great Cultural Revolution and the expansion of the great leap forward thinking, Chinese social and economic sustained depression in S2 and S3, expansive negative decoupling appears in China from S2 to S3; continuous weak decoupling occurred from S4 to S7 (1978-2001), in which China supported a lower growth rate of carbon dioxide emissions from the rapid economic growth; there is a slight rebound in S8, China carbon dioxide emissions increase faster than economic growth, expansive coupling appears in this stage.

Expansive negative decoupling appears in India in S1, S3 and S5, expansive coupling appears in S6, weak decoupling occurs in S2, S7 and S8, in generally speaking, India decoupling elasticity values showed a slow decline trend. Compared with China, the case of India is a typical case which showed a continuous and logical development trend. However, decoupling relationships between carbon dioxide emissions and economic growth in 8 sub-stages in Brazil is very unstable compared with the case of China and India. Expansive coupling appeared in S1, S3 and S5 in Brazil, due to the external debt burden of inflation, balance of payments deficit, the 
Brazilian government had to take the "cooling-off" economic policy which slow down the pace of economic development in the 1980s; strong decoupling occurs in S4 (1978-1983), as a matter of fact, Brazil has experienced an unprecedented recession from 1981 to 1983, which is the main reason of Brazilian strong decoupling between carbon dioxide emissions and economic growth; Brazilian industrial production has shown signs of recovery, and food production has been a bumper crop in the 1990s, so expansive negative decoupling appeared in Brazil in S6 and S7 (1990-2001); because Brazil government dedicated to develop bio-energy technologies and achieved optimistic achievements, which made its carbon dioxide emissions growth curbed, weak decoupling appears in S8 (2002-2007). Generally speaking, Brazil decoupling elasticity has been fluctuated significantly from 1960 to 2007.

(4) Decoupling elasticity development characteristics in developed countries differ greatly from that in developing countries

There are huge decoupling elasticity development characteristics' differences between developed countries and developing countries. From the perspective of decoupling elasticity value, decoupling elasticity value in developing countries in 8 sub-stages are significantly higher than that in developed countries in the corresponding sub-stages. In developing countries, weak decoupling occurs from S4 to S7 in China, the same weak decoupling appears in S2, S7 and S8 in India, Brazil only in S8 appeared weak decoupling, and the only time appeared a strong decoupling phenomenon in developing countries is because of the economic recession. Therefore we can make a conclusion that there is no real strong decoupling appears in developing countries in the entire study period, developing countries' carbon dioxide emissions may still continue to grow in the future decades. In comparison, strong decoupling and weak decoupling occur in 6 developed countries in most time of 8 sub-stages, which imply that it is very difficult to achieve strong decoupling between carbon dioxide emissions and economic growth in the basis of a low national income, developing countries in the process of industrialization still need time to achieve the decoupling achievements of developed countries which have already finished industrialization or would accomplished industrialization in a short time, hence economic development in developing countries will still accompany with carbon dioxide emissions' increase in a long period.

\section{Conclution and Discussion}

\subsection{Conclusion}

According to theoretical analysis on decoupling theory and decoupling empirical study focus on 6 developed countries and 3 developing countries, conclusions can be drawn as following:

- 6 developed countries are all at least experienced once strong decoupling between carbon dioxide emissions and economic development in 8 sub-stages. French performance is the most prominent in 6 developed countries, strong decoupling occurred in France 5 times, in United Kingdom and Sweden 4 times respectively. Most of the developed countries experienced strong decoupling in S4 and S7.

- 6 developed countries' decoupling trends are basically consistent in 8 sub-stages, which indicates that it is possible to achieve the continuous and stable separation of economic growth and carbon dioxide emissions.

- Decoupling development trends appeared a big difference in 3 typical developing countries. Weak decoupling occurred in China from S4 to S7, meanwhile decoupling elasticity values were gradually declining, then there is a slight rebound in S8, China experienced extensive coupling in the last stage; decoupling elasticity values in India are higher than China in 8 sub-stages, but the pace of India pursuing decoupling is the most stable among 3 developing countries; Brazil decoupling elasticity has been fluctuated significantly from 1960 to 2007.

- Decoupling elasticity development characteristics in developed countries differed greatly from that in developing countries. Decoupling elasticity in developing countries is significantly higher than in developed countries in the entire target research phase; it will be take a long time for developing countries to achieve developed countries' decoupling achievements.

\subsection{Discussion}

- Target research period selected in this article is still not long enough, more decoupling characteristics between carbon emissions and economic growth in a longer period need to be to be further observed.

- Pursuit of achieving strong decoupling between economic growth and carbon emissions should not at the expense of economic regression or economic stagnation, strong decoupling in Brazil in S4 is 
not a satisfying case.

- Decoupling theory is a good tool to describe the dynamic changes in the relationship between economic development and carbon dioxide emissions, it will give a certain inspiration to establish a low-carbon indicators system which is the work we will do in next step.

- Although we made a conclusion that it will be take a long time for developing countries to achieve developed countries' decoupling achievements, due to the rise of green technology and green markets, developing country may capable to master the advantages of a late comer, which will shorten the time developing country realizing its strong decoupling. How to realize global low carbon leadership in the future by the way of green technology will be a good research topic.

\section{Acknowledgement}

This article is supported by CAS Strategic Priority Research Program-Carbon Budget and Related Issues: Policy Simulation Forum for dealing with Climate Change and National Development (sub-project 4) (XDA05150401) and The Knowledge Innovation Program of the Chinese Academy of Sciences (Grant No.kzcx2-yw-325).

\section{References}

Annabelle, G. (2007). A Discussion on Decoupling Economic Growth from the Emissions of Carbon Dioxide. Retrieved from http://www.ew.govt.nz/PageFiles/6131/tr07-02.pdf

Andreoni, S., \& Galmarini. (2012). Decoupling economic growth from carbon dioxide emissions: A decomposition analysis of Italian energy consumption. Energy. http://dx.doi.org/10.1016/j.energy.2012.05.024

CDIAC. (2010). http://cdiac.ornl.gov/trends/emis/meth_reg.html

Huang, W. M., Lee, G. W. M., \& Wu, C. C. (2008). GHG emissions, GDP growth and the Kyoto Protocol: a revisit of environmental Kuznets curve hypothesis. Energy Policy, 36, 239-247. http://dx.doi.org/10.1016/j.enpol.2007.08.035

Jon, T. S. (2001). Economic instruments for decoupling environmental pressure from economic growth. Retrieved from www.norden.org/mijoe/Miljo-okonomi/porsjekt/prosjek-tskisser/sk/Decou071.PDF

Julia, K., Steinberger, J., \& Timmons, R. (2010). From constraint to sufficiency: The decoupling of energy and carbon from human needs, 1975-2005. Ecological Economics. http://dx.doi.org/10.1016/j.ecolecon.2010.09.014

Li, J. M., Sun, Y. L., Zhuang, M. F. (2005). Taiwan carbon dioxide emissions decoupling indicators construction and evaluation. China Development Fund Management Committee: The Paper Collection of Cross-Strait Environmental Protection and Sustainable Development Seminar.

Marzio, G. (2003). Environment and Economic Growth: Is Technical Change the Key to Decoupling? FEEM Working Paper No.90.2003. Retrieved from http://ssrn.com/abstract=465221

OECD. (2002). Indicators to measure decoupling of environmental pressure form economic growth. Retrieved from http://www.oecd.org/officialdocuments/publicdisplaydocumentpdf/?cote=SG/SD(2002) 1/FINAL\&docLanguage $=$ En

Petri, T. (2005). Towards a theory of decoupling: degrees of decoupling in the EU and case of road traffic in in

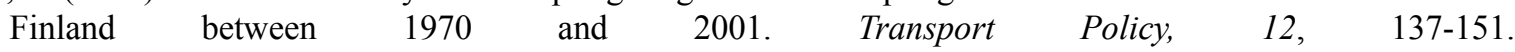
http://dx.doi.org/10.1016/j.tranpol.2005.01.001

United Nations Environment Programme. (2010). http://geodata.grid.unep.ch/

Vehmas, J., Malaska, P., Luukkanen, J., Kaivo-oja, J., Hietanen, O., Vinnari, M., \& Ilvonen, J. (2003). Europe in the global battle of sustainability: Rebound strikes back?-Advanced Sustainability Analysis, Publications of the Turku School of Economics and Business Administration, Series Discussion and Working Papers 7:2003, Turku.

Voet, E. van der, Oers, L. van, Moll, S., Schütz, H., Bringezu, S., Bruyn, S. de, ... Warringa, G. (2005). Policy Review on Decoupling: Development of indicators to assess decoupling of economic development and environmental pressure in the EU-25 and AC-3 countries. Retrieved from http://ec.europa.eu/environment/natres/pdf/fin_rep_natres.pdf

Wang, C. M. (2010). Decoupling analysis of China economic growth and energy consumption. China Population. Resources and Environment, 20(3), 35-37. 
Ru, X. J., Chen, S. F., Liu, Y., \& Su, L. Y. (2012). A Study on Evolution and Driving forces of Carbon Dioxide Emissions. Journal of Sustainable Development, 5(5), 111-120. http://dx.doi.org/10.5539/jsd.v5n5p111

Yang, K., Chen, B. M., Song, W. (2009). Decoupling Analysis between Arable Land Occupation and GDP Growth in Hebei Province. Resource Science (China), 31(11), 1940-1946.

Zhuang, G. Y. (2007). Low-carbon economy: China's development road in the context of climate change. Beijing: Meteorology Press.

\section{Notes}

Note 1. CA, FR, JP, SE, UK, US, CN, IN and BR in Figure 3 represent Canada, France, Japan, Sweden, United Kingdom, United States, China (Mainland), India, Brazil respectively.

Note 2. 1, 2, 3, 4, 5, 6, 7, 8 in Figure 3 represent S1-S7 respectively.

Note 3. China decoupling elasticity value in $\mathrm{S} 1$ is very high, which will affect the overall display effect, so China decoupling elasticity value in $\mathrm{S} 1$ is not showed in Figure 5. 